\title{
ARTICLE \\ Recombinant Bcl-xL attenuates vascular hyperpermeability in a rat model of hemorrhagic shock
}

\author{
B Tharakan ${ }^{1}$, SI McNeal ${ }^{2}$, FA Hunter ${ }^{2}$, DA Sawant ${ }^{3}$, WR Smythe ${ }^{4}$ and EW Childs ${ }^{2}$
}

Following hemorrhagic shock (HS), vascular hyperpermeability, that is, the leakage of fluid, nutrients and proteins into the extravascular space occurs primarily due to the disruption of the endothelial cell-cell adherens junctional complex. Studies from our laboratory demonstrate that activation of the mitochondria-mediated 'intrinsic' apoptotic signaling cascade has a significant role in modulating HS-induced hyperpermeability. Here we report the novel use of recombinant $\mathrm{Bcl}-\mathrm{xL}$, an anti-apoptotic protein, to control HS-induced vascular hyperpermeability. Our results corroborate involvement of vascular hyperpermeability and apoptotic signaling. HS (the mean arterial pressure (MAP) was reduced to $40 \mathrm{~mm} \mathrm{Hg}$ for $60 \mathrm{~min}$ followed by resuscitation to $90 \mathrm{~mm} \mathrm{Hg}$ for $60 \mathrm{~min}$ ) in rats resulted in vascular hyperpermeability as determined by intravital microscopy. Treatment of $\mathrm{Bcl}-\mathrm{xL}(2.5 \mu \mathrm{g} / \mathrm{ml}$ of rat blood in non-lipid cationic polymer, i.v.) before, during and even after HS attenuated or reversed HS-induced vascular hyperpermeability significantly $(P<0.05)$. Conversely, treatment using Bcl-xL inhibitors, 2-methoxy antimycin (2-OMeAA) and ABT 737, significantly increased vascular hyperpermeability compared with sham $(P<0.05)$. Bcl-xL treatment also decreased the amount of fluid volume required to maintain a MAP of $90 \mathrm{~mm} \mathrm{Hg}$ during resuscitation $(P<0.05)$. HS resulted in an increased mitochondrial reactive oxygen species formation, reduction of $\Delta \psi \mathrm{m}$, mitochondrial release of cytochrome $c$ and significant activation of caspase-3 $(P<0.05)$. All of these effects were significantly inhibited by Bcl-xL pre-treatment $(P<0.05)$. Our results show that recombinant Bcl-xL is effective against HS-induced vascular hyperpermeability that appears to be mediated through the preservation of $\Delta \psi \mathrm{m}$ and subsequent prevention of caspase-3 activation.

Cell Death Discovery (2015) 1, 15042; doi:10.1038/cddiscovery.2015.42; published online 9 November 2015

\section{INTRODUCTION}

One of the clinical manifestations of hemorrhagic shock (HS) is disruption of the vascular endothelial cell barrier, which leads to the leakage of fluid, nutrients and proteins into the extravascular space. ${ }^{1}$ Leakage of fluids into third spaces during HS leads to lowered cardiac output and hypoperfusion of vital organs. If left untreated, the organs will begin to fail. HS accounts for nearly $30 \%$ of the deaths associated with traumatic injury. ${ }^{2}$ HS following trauma is shown to induce reactive oxygen species (ROS) formation and activation apoptotic signaling in the endothelium. ${ }^{3-6}$ Our laboratory is interested in the involvement of apoptotic signaling as a key regulator of vascular permeability following HS. ${ }^{7-9}$ We have shown that infusion of the pro-apoptotic protein BAK induces vascular hyperpermeability in rats at comparable levels to a model of HS. ${ }^{10}$ Further studies were undertaken that shows $\mathrm{Bcl}-\mathrm{xL}$ abrogates the paracellular hyperpermeability initiated by tumor necrosis factor $a$ (TNFa) in vitro. ${ }^{8}$ From these data, we hypothesized that $\mathrm{BCl}-\mathrm{xL}$ can be used as a therapeutic during HS. In this study, we use a novel in vivo protein transference method ${ }^{9,11}$ to introduce recombinant mouse $\mathrm{BCl}-\mathrm{xL}$ $(\mathrm{rBCl}-\mathrm{xL})$ into exchange vessels and monitor change in HS-induced vascular hyperpermeability. We also monitor mitochondrial ROS formation and membrane potential in vivo, utilizing dihydrorhodamine 123 and JC- 1 (5,5'6, 6'-tetrachloro-1,1',3,3'tetraethylbenzimidazolyl-carbocyanine iodide), respectively, and investigate the release of cytochrome $c$, and activation of caspase-3. We also perform in vitro parallel studies in microvascular endothelial cells.
Our results demonstrate that exogenous delivery of $r B c l-x L$ effectively prevents HS-induced vascular hyperpermeability in rats and is mediated via inhibition of the intrinsic apoptotic signaling cascade.

Apoptosis classically follows two pathways: the extrinsic (external stimuli) and the intrinsic (internal stimuli). ${ }^{12,13}$ The extrinsic pathway of apoptosis is initiated by binding the extracellular receptors in the TNF receptor superfamily, commonly referred to as the death receptors, for example, Fas, TNF $a$ and TNF-related apoptosis-inducing ligand (TRAIL). ${ }^{13,14}$ The intrinsic pathway is activated by internal cellular damage, for example, hypoxia, ischemia and ROS generation. ${ }^{15-18}$ The result of activation is the release of cytochrome $c$ from the mitochondria forming the apoptosome and activating caspase 9. Activated mitochondria release cytochrome $c$, apoptosis-inducing factor and second mitochondrial-derived activator of caspases, all of which are regulated by members of the $\mathrm{Bcl}-2$ family of proteins $(14,51)$. The $\mathrm{BCl}-2$ family consists of both anti-apoptotic (BCl-2, BCl-xL and mcl-1) and pro-apoptotic (BAK and BAX) members ${ }^{15,19,20}$ Therefore, mitochondrial ROS is believed to have an important role in mitochondria-mediated intrinsic apoptotic signaling.

\section{RESULTS}

$\mathrm{rBCl}-\mathrm{xL}$ treatment attenuated vascular hyperpermeability following $\mathrm{HS}$ in rats

We have established that HS induces vascular hyperpermeability in mesenteric post-capillary venules. Here we observe a significant

\footnotetext{
${ }^{1}$ Department of Surgery, Texas A\&M University Health Science Center College of Medicine, Baylor Scott and White Healthcare, Temple, TX, USA; ${ }^{2}$ Department of Surgery, Morehouse School of Medicine, Atlanta, GA, USA; ${ }^{3}$ School of Anatomical Science, Alderson Broaddus University, Philippi, WV, USA and ${ }^{4}$ AVIA Health Innovation, Chicago, IL, USA. Correspondence: EW Childs (echilds@msm.edu)
}

Received 17 August 2015; accepted 29 August 2015; Edited by AE Sayan 
increase in extravasation of fluorescein isothiocyanate-bovine albumin (FITC-albumin) into the extravascular space versus the sham-operated animals $(P<0.05 ; n=5$; Figure 1a). When we inject $\mathrm{rBCl}-\mathrm{xL}$, an anti-apoptotic protein, before, during and after the $\mathrm{HS}$ period, we observe a significant attenuation of hyperpermeability compared with the HS group without $\mathrm{Bcl}-\mathrm{xL}$ treatment $(P<0.05$; $n=5$; Figure $1 \mathrm{~b}$ ). Change in fluorescence intensity $(\Delta l)$ in the $\mathrm{rBcl}-$ $x \mathrm{~L}$ treatment groups increases depending on the time in which $\mathrm{rBcl}-\mathrm{xL}$ is injected. Although the $\Delta l$ increases, none of the $\mathrm{rBcl}-\mathrm{xL}$ treatment groups are statistically different from sham. Exogenous administration of anti-apoptotic protein $\mathrm{Bcl}-\mathrm{xL}$ reduces the mesenteric post-capillary venule hyperpermeability associated with HS.

\section{$\mathrm{BCl}-\mathrm{xL}$ transfection is sufficient to increase vascular permeability} in vivo

To determine whether the reduction of vascular hyperpermeability is due to the transfection of $\mathrm{BCl}-\mathrm{xL}$, we utilize the $\mathrm{Bcl}-\mathrm{xL} / \mathrm{Bcl}-$ 2 inhibitors 2-OMeAA and ABT 737. Both treatment groups show significant increases in vascular hyperpermeability compared with the untreated sham group (Figures $1 \mathrm{c}$ and d). The FITC-albumin fluorescence intensity in the 2-OMeAA-treated group shows a time-dependent increase starting at $30 \mathrm{~min}(P<0.05$; Figure $1 \mathrm{c})$. The FITC-albumin fluorescence intensity in the ABT 737-treated group shows a time-dependent increase starting at $10 \mathrm{~min}$ $(P<0.05$; Figure 1d).
$\mathrm{Bcl}-\mathrm{xL}$ transfection reduces the amount of resuscitation fluid post HS

To better understand the clinical significance of $\mathrm{BCl}-\mathrm{xL}$ attenuation of HS-induced vascular permeability, we evaluated the volume of fluid necessary to resuscitate our animals following HS. Bcl-xL significantly reduced the fluid requirement compared with the HS-alone group ( $P<0.05$, Figure $1 \mathrm{e})$.

\section{Recombinant $\mathrm{Bcl}-\mathrm{xL}$ attenuates mitochondrial ROS formation} in vivo

$\mathrm{BCl}-\mathrm{xL}$ prevents apoptosis by sequestering pro-caspases or preventing the release of mitochondrial apoptogenic factors. In contrast, the pro-apoptotic members of this family, such as BAK, trigger the release of mitochondrial apoptogenic factors into the cytoplasm by acting on the mitochondrial transition pore (MTP). We also reported that this increase in endothelial ROS following HS is associated with an increase in microvascular hyperpermeability. We have demonstrated in vitro that ROS activation of the mitochondria has been shown to result in the release of apoptogenic factors such as cytochrome $c^{21}$

Utilizing the ROS-specific dye DHR 123, we took images of a sham rat's mesenteric post-capillary venule demonstrating minimal ROS formation (Figure 2a, left panel). Following 60 min of HS and 60 min of resuscitation $\left(T_{60}\right)$ we observe a significant increase in ROS formation (Figure $2 \mathrm{a}$, middle panel). $r B c l-x L$ pre-

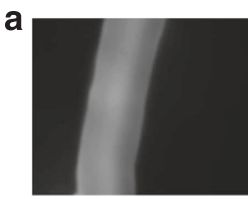

Sham

b

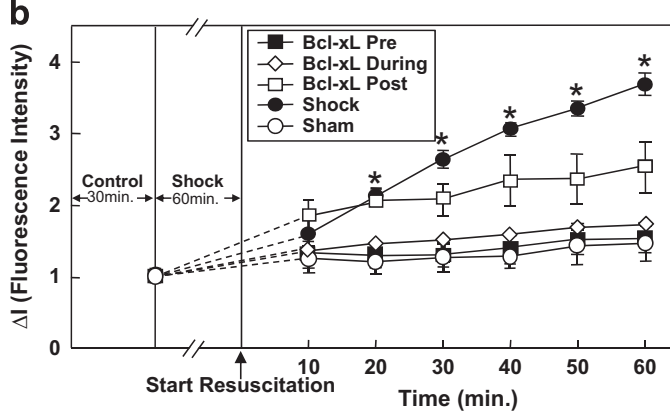

d

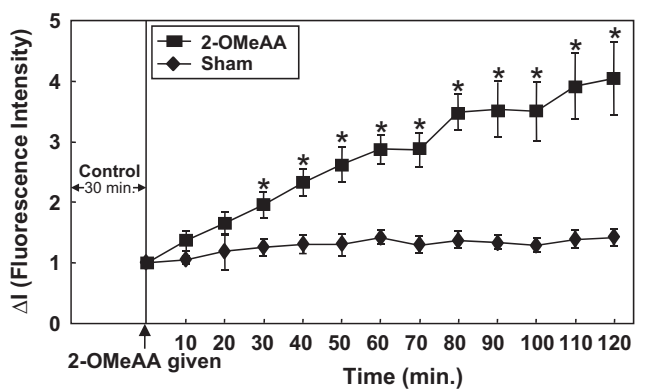

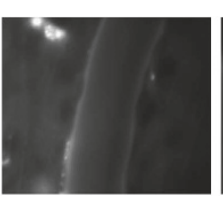

Shock $\mathrm{T}_{60}$

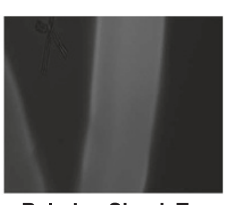

Bcl-xL + Shock $T_{60}$
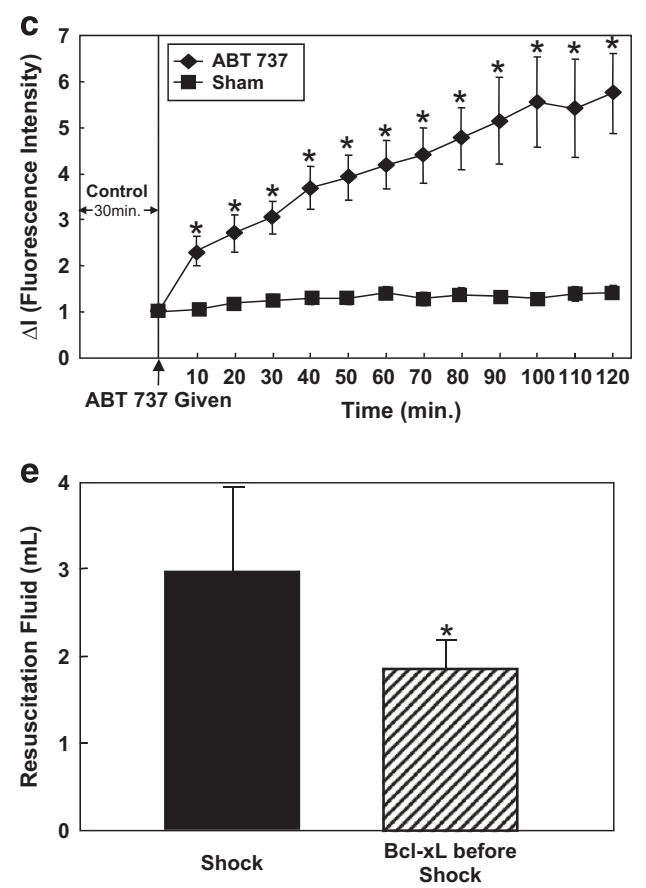

Figure 1. $\mathrm{rBcl}-\mathrm{xL}$ prevents $\mathrm{HS}$-induced vascular hyperpermeability in rat mesentery. (a) Representative mesenteric post-capillary venules from sham, $\mathrm{HS}$ for $1 \mathrm{~h}\left(T_{60}\right)$ and Bcl-xL pre-treatment in shock are shown (b-d) FITC-albumin extravasation into the extravascular space is measured following HS. (b) All treatment arms of $\mathrm{rBCl}-\mathrm{xL}$ are not significantly different from Sham. FITC-albumin extravasation is significantly high and time-dependent, following HS $(P<0.05 ; n=5)$. (c) The Bcl-xL inhibitor 2-OMeAA induces vascular hyperpermeability in a similar manner as HS $(P<0.05 ; n=5)$. (d) The BH3 inhibitor ABT 737 induces vascular hyperpermeability in a similar manner as $\mathrm{HS}(P<0.05 ; n=5)$. $(\mathbf{e}) \mathrm{rBcl}-\mathrm{xL}$ treatment reduced the amount of resuscitation fluid required to achieve a MAP of $40 \mathrm{~mm} \mathrm{Hg}$. ${ }^{*}$ Significant difference versus hemorrhagic shock group and $\mathrm{BCl}-\mathrm{xL}$ plus hemorrhagic shock groups $(P<0.05)$. 


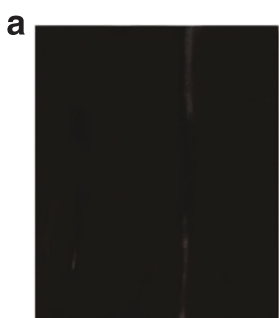

Sham

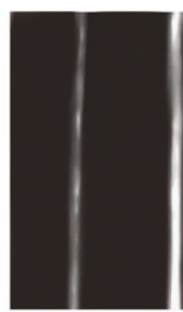

ShockT $_{60}$
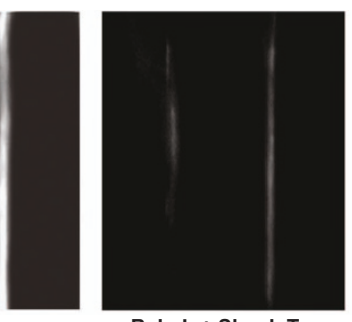

Bcl-xL + Shock $\mathrm{T}_{60}$
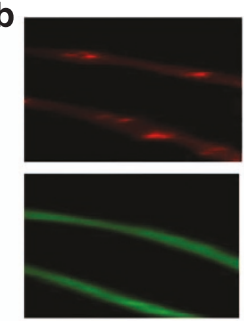

Sham
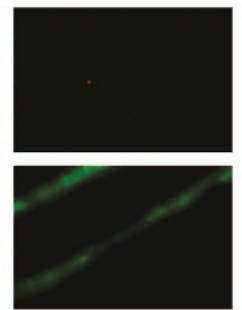

Shock $\mathrm{T}_{60}$

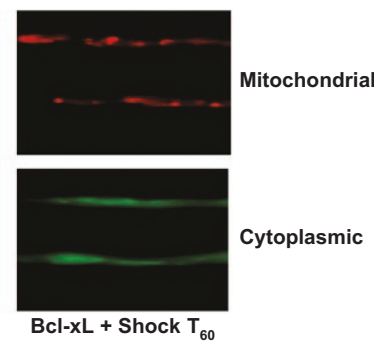

d
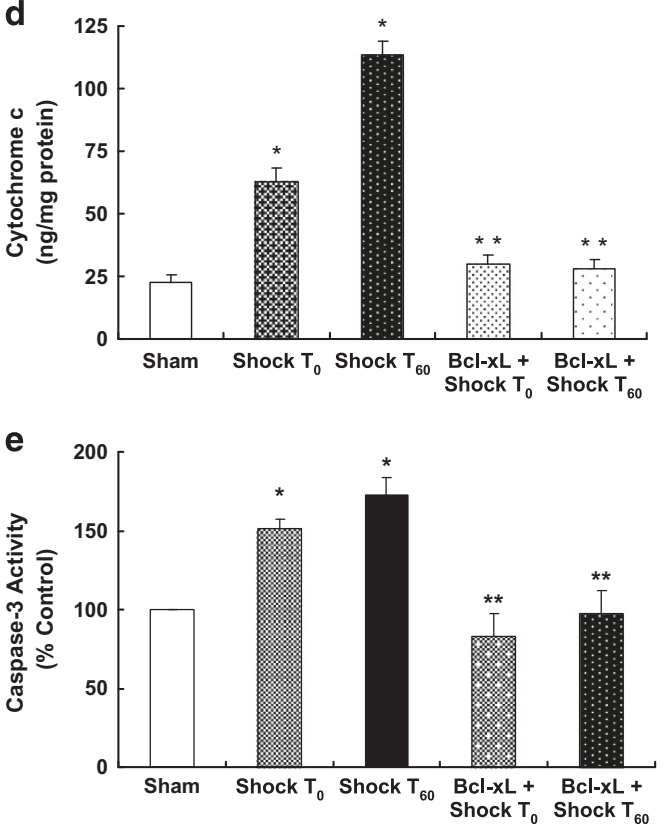

Figure 2. $r B c l-x L$ prevents HS-induced mitochondrial ROS formation and cytochrome $c$ release in the rat mesentery. (a) Representative images of mesenteric post-capillary venules of sham, Shock $T_{60}$ and $\mathrm{rBcl}-\mathrm{xL}$ treatment $10 \mathrm{~min}$ before $\mathrm{HS}$ (Bcl-xL+Shock $T_{60}$ ) are shown. (b) $\mathrm{Change}$ in fluorescence intensity of mesenteric post-capillary venules of sham, shock and Bcl-xL+Shock are shown. Significantly increased ROS formation is observed following hemorrhagic shock compared with the sham group $(P<0.05 ; n=5)$, whereas rBcl-xL treatment maintains sham levels of ROS. (c) rBcl-xL prevents hemorrhagic shock-induced decrease in $\Delta \psi_{\mathrm{m}}$. In sham, the JC-1 fluoresces red inside the mitochondria (top left panel) and the cytoplasm green (bottom left panel) indicating $\Delta \psi_{\mathrm{m}}$. Shock $T_{60}$ demonstrates a loss $\Delta \psi_{\mathrm{m}}$ (top middle panel) Bcl-xL + Shock $T_{60}$ treatment maintains $\Delta \Psi_{\mathrm{m}}$ (top right panel). (d) $\mathrm{Bcl}$-xL inhibits HS-induced cytochrome $c$ release in the mesenteric vasculature. Cytosolic cytochrome $c$ levels increase significantly at 0 and $60 \mathrm{~min}$ after resuscitation compared with sham. rBcl-xL inhibited hemorrhagic shockinduced increase in cytochrome $c$ levels significantly $\left({ }^{*} P<0.05\right.$ versus sham group; ${ }^{* *} P<0.05$ versus shock group). (e) $\mathrm{rBcl}-\mathrm{xL}$ inhibits hemorrhagic shock-induced caspase- 3 activation in the mesenteric vasculature. Caspase- 3 activity increases significantly after shock at 0 and 60 min after resuscitation compared with sham. Bcl-xL inhibited hemorrhagic shock-induced caspase-3 activation significantly $\left({ }^{*} P<0.05\right.$ versus sham group; $n=5 ;{ }^{* *} P<0.05$ versus shock group).

treatment attenuates ROS formation and the $\Delta l$ is not dissimilar to Sham $\Delta I$ (Figure 2a, right panel). To further assess the role of $\mathrm{Bcl}-\mathrm{xL}$ we assayed the amount of ROS produced by exogenous delivery of $\mathrm{rBcl}-\mathrm{xL}$ during $\mathrm{HS}$. In rats, HS results in a significant increase in mitochondrial ROS formation compared with the sham-control group ( $P<0.05$; Figure $2 \mathrm{~b}$ ). Bcl-xL pre-treatment, that is, $10 \mathrm{~min}$ before the HS period results in a significant attenuation of ROS formation compared with the HS group that did not receive $\mathrm{rBcl}-$ $\mathrm{xL}(P<0.05$; Figure $2 \mathrm{~b})$.

Recombinant $\mathrm{Bcl}-\mathrm{xL}$ decreased mitochondrial transmembrane depolarization in vivo

To determine the role that exogenous $\mathrm{Bcl}-\mathrm{xL}$ has on the $\Delta \psi_{\mathrm{m}}$ we utilized $\mathrm{JC}-1$ as described previously. ${ }^{10,22} \mathrm{~A}$ mesenteric post-capillary venule from a sham-control rat demonstrates both green (cytosolic) and red (mitochondrial) fluorescence in the vascular endothelial cells (Figure 2c, left panels). Following $\mathrm{HS}$ and $60 \mathrm{~min}$ of resuscitation, there was a decrease in red (mitochondrial) fluorescence indicating the loss of $\Delta \Psi_{\mathrm{m}}$
(Figure 2c, middle panels). $\mathrm{Bcl}-\mathrm{xL}$ pre-treatment prevented the loss of $\Delta \psi_{\mathrm{m}}$ evident by the increase in red fluorescence compared with the HS group without $\mathrm{BCl}-\mathrm{xL}$ treatment (Figure 2c, right panels).

Recombinant $\mathrm{Bcl}-\mathrm{xL}$ decreased mitochondrial cytochrome $c$ release

Release of cytochrome $c$ from mitochondria into the cytosol through the MTP is the major route of caspase activation. Cytoplasmic cytochrome $c$ leads to the release of the apoptosome assembly from apoptotic protease-activating factor-1 (Apaf-1), ATP and procaspase-9, which ultimately activates the effector caspase. ${ }^{23}$ Thus, alterations in mitochondrial membrane integrity via pro-apoptotic factors and the subsequent release of cytochrome $c$ are the key components in the apoptotic signaling cascade. Previous studies from our laboratory implicated the mitochondria of endothelial cells as a major producer of ROS following $\mathrm{HS}^{24}$ Release of cytochrome $c$ from the mitochondria into the cytosol following the opening of the MTP has been 
reported to be the key event in apoptosis induced by various stimuli. In our data, cytoplasmic cytochrome $c$ levels are elevated following $\mathrm{HS}$ at $T_{0}$ (60 min of $\mathrm{HS}$ and 0 min resuscitation) and at $T_{60}$ ( $60 \mathrm{~min}$ of $\mathrm{HS}$ and $60 \mathrm{~min}$ of resuscitation) compared with sham-control group $(P<0.05)$. The $r B c l-x L-p r e-t r e a t e d ~ H S$ group ( $T_{0}$ and $T_{60}$ ) shows significantly lower levels of cytoplasmic cytochrome $c$ compared with the HS group without $\mathrm{rBcl}-\mathrm{xL}$ treatment $(P<0.05$; Figure $2 \mathrm{~d})$.

Recombinant $\mathrm{BCl}-\mathrm{xL}$ attenuated caspase-3 activation HS groups $T_{0}$ and $T_{60}$ show significant increase in caspase-3 activity compared with sham-control group ( $P<0.05$; Figure $2 \mathrm{e}$ ). $\mathrm{rBcl}-\mathrm{xL}$ treatment before HS shows significantly lower caspase-3 activity compared with $\mathrm{HS}$ without $\mathrm{BCl}-\mathrm{xL}$ pre-treatment $(P<0.05$; Figure 2e).
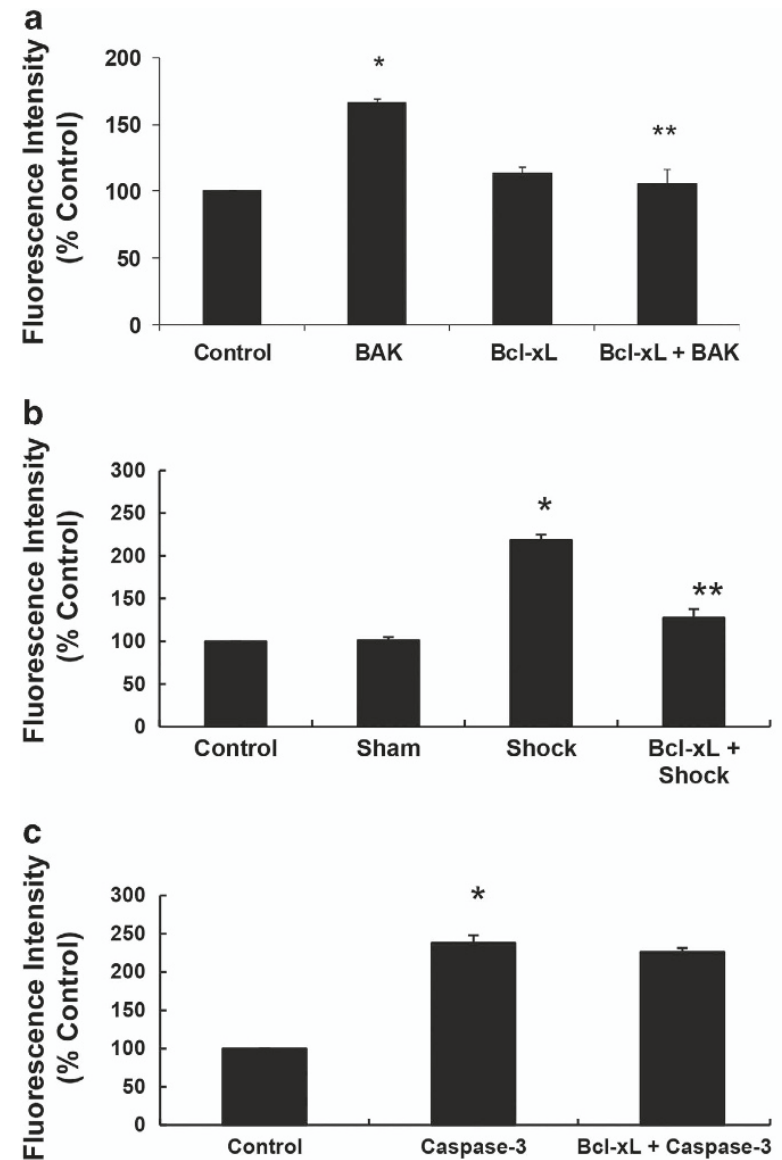

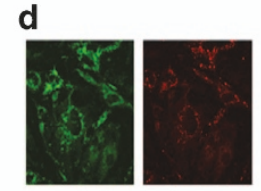

Control

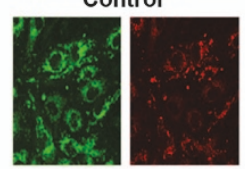

Sham

e

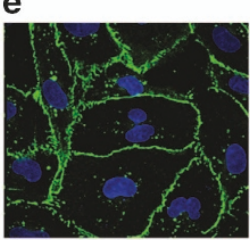

Control

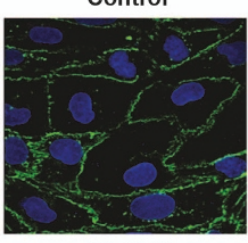

TransIT

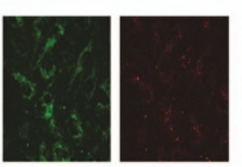

Shock

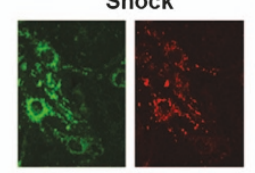

Bcl-xL + Shock

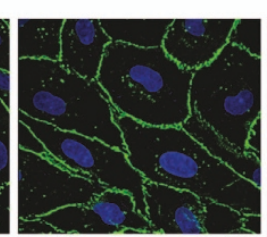

Sham

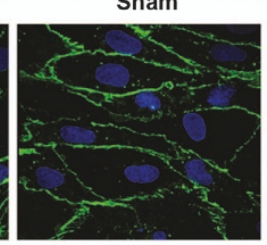

Bcl-xL + Sham

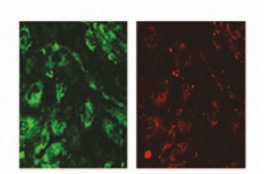

Bcl-xL

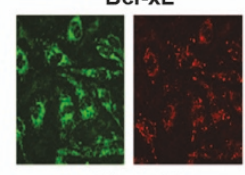

TransIT

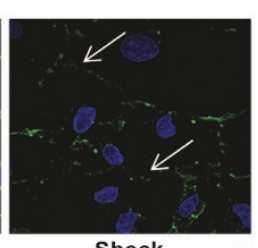

Shock

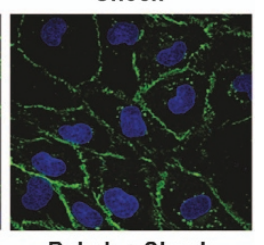

Bcl-xL + Shock

Figure 3. $r B C l-x L$ attenuates BAK-induced hyperpermeability in RLMEC monolayers. (a) Change in permeability is expressed as percentage of the basal fluorescence. BAK transfection induced hyperpermeability in the monolayer compared with control (*P< $<0.05 ; n=5)$. Bcl-xL pre-treatment in BAK-transfected cells showed decrease in FITC-albumin fluorescence compared with untreated cells $(* * P<0.05$; $n=5$ ). (b) $\mathrm{rBCl}-\mathrm{xL}$ attenuates shock serum-induced hyperpermeability in RLMEC monolayers. The fluorescence intensity is significantly higher in the shock serum-treated group compared with the control group or sham serum-treated group showing an increase in permeability of the monolayer. The monolayers pre-treated with $\mathrm{rBcl}-\mathrm{xL}$ attenuated the shock serum-induced hyperpermeability significantly. (c) $\mathrm{rBcl}$-xL acts upstream of caspase-3-induced hyperpermeability in rat lung microvascular endothelial cell monolayers. The FITC-albumin fluorescence intensity is significantly higher in the active caspase-3-transferred group compared with the control group $(P<0.05)$, suggesting an increase in permeability of FITC-albumin across the endothelial cell monolayer. The monolayers pre-treated with $\mathrm{rBcl}-\mathrm{xL}$ show no significant decrease in hyperpermeability. (d) Bcl-xL protects mitochondrial membrane integrity in RLMECs. Fluorescence microscopy images of the mitochondrial membrane potential indicator JC-1 in its monomeric (green) and dimeric (red) forms are shown. Treatment of HS serum leads to the loss of $\Delta \psi_{\mathrm{m}}$, showing predominantly monomeric forms. Bcl-xL treatment prevents the collapse of mitochondrial membrane potential evidenced by the restoration of dimeric form-red fluorescence. (e) $\mathrm{rBcl}-\mathrm{xL}$ protects endothelial adherens junction complex from hemorrhagic serum-induced disruption in rat lung microvascular endothelial cell monolayers. Shock serum treatment shows disruption of adherens junction evident from diffused fluorescence of $\beta$-catenin as well as intercellular gap formations. The cells pre-treated with Bcl-xL did not show a visible change in $\beta$-catenin distribution at the adherens junction indicating intact barrier functions. Bcl-xL transference or TransIT alone treatment showed no visible change in $\beta$-catenin distribution compared with untreated control cells. 
untreated control group show red fluorescence indicating J-aggregate formation and intact mitochondria (Figure 3d, top left). Sham serum, Bcl-xL or TransIT-alone treatments show no visible change in mitochondrial transmembrane potential compared with untreated control monolayers (Figure 3d). Following HS serum treatment, there is a decrease in mitochondrial (red) fluorescence indicating the loss of MTP. RLMEC monolayers treated with $\mathrm{HS}$ serum and $\mathrm{rBCl}-\mathrm{xL}$ maintain red fluorescence, which indicates the preservation of the MTP (Figure $3 \mathrm{~d}$, middle panel).

$B C l-x L$ prevents adherens junction damage in microvascular endothelial cells. RLMEC from the untreated control group and the sham serum-treated group displays continuous distribution of FITC- $\beta$-catenin at the adherens junctional complex (Figure 3e). Following HS serum treatment, the adherens junctions are disrupted as evidenced by diffused punctuate distribution of $\beta$ catenin and formation of intercellular gaps (Figure 3e, top right). HS serum-treated cells pre-treated with $\mathrm{rBCl}-\mathrm{xL}$ prevents the disruption of $\beta$-catenin at the adherens junction (Figure $3 e$, bottom right).

\section{DISCUSSION}

Death receptors are known to be activated during ischemiareperfusion injury in the microvasculature. In particular, the TNF and TRAIL receptors become activated and initiate both death and pro-survival signaling. ${ }^{26}$ By definition, our experimental model of HS produces a period of ischemia followed by a reperfusion event. Using this model, our laboratory has shown a direct correlation between apoptotic signaling and HS-induced vascular hyperpermeability. ${ }^{10}$ Specifically, transfection of the pro-apoptotic $\mathrm{Bcl}-2$ family member BAK is sufficient to initiate hyperpermeability of the mesenteric vasculature in rats following $\mathrm{HS}^{8}{ }^{8}$ Here we report that exogenous delivery of the $\mathrm{rBcl}-\mathrm{xL}$ protein, a member of the $\mathrm{Bcl}-2$ family of proteins, attenuates vascular hyperpermeability, mitochondrial depolarization, ROS production and the activation of caspase- 3 in rats following experimental HS.

All members of the $\mathrm{BCl}-2$ family share one or more $\mathrm{BCl}-2$ homology $(\mathrm{BH})$ domains and are divided into two main groups according to whether they are pro- or anti-apoptotic. The proapoptotic members of the $\mathrm{Bcl}-2$ family are subdivided according to whether they contain multiple $\mathrm{BH}$ domains or only the required $\mathrm{BH} 3$ domain. The pro-apoptotic protein BAK is a multidomain $\mathrm{BH} 3$ protein that induces loss of $\Delta \Psi_{\mathrm{m}}$ via the mitochondrial permeability transition pore. ${ }^{27}$ BAK and BAX oligomerization is important for the permeabilization of the mitochondrial outer membrane. In our study, rBcl-xL attenuated BAK-induced monolayer hyperpermeability and presumably in the mesenteric vasculature, given the significantly lower levels of detection of ROS and mitochondrial depolarization (see Figures $2 b$ and $c$ ). $\mathrm{BCl}-\mathrm{xL}$ is known to antagonize the effects of pro-apoptotic BAK at the level of mitochondria, and the protection by $\mathrm{BCl}-\mathrm{xL}$ observed in this study may be attributed to its protective effect against BAK-induced permeabilization of mitochondrial membrane. Our recent studies have shown that BAK peptide induces vascular hyperpermeability in rats. $^{10}$ Furthermore, collapse of $\Delta \Psi_{\mathrm{m}}$ mitochondrial release of cytochrome $c$ into the cytoplasm and the activation of caspase- 3 occurs following BAK peptide treatment. We suspect that overexpression of an anti-apoptotic protein such as $\mathrm{BCl}-\mathrm{xL}$ is outcompeting $\mathrm{BAK}$ and $\mathrm{BAX}$ for their binding site, preventing their oligomerization and opening of the MTP.

Further support for apoptosis having a major role in vascular permeability was confirmed by the observation that the specific $\mathrm{BCl}-\mathrm{xL}$ inhibitor and a pan-BH3 inhibitor, 2-OMeAA and ABT 737, respectively, induced vascular hyperpermeability following $\mathrm{BCl}-\mathrm{xL}$ transcription in the rat (see Figures $1 \mathrm{c}$ and d). We demonstrate the therapeutic usefulness of $\mathrm{BCl}-\mathrm{xL}$ in $\mathrm{HS}$ by observing that administration of $\mathrm{rBCl}-\mathrm{xL}$ reduces the amount of fluid required for resuscitation following HS, that is, less vascular permeability (see Figure 1e). Thus, our study shows the effectiveness of $\mathrm{Bcl}-\mathrm{xL}$ treatment against HS-induced microvascular hyperpermeability by inhibition of the intrinsic apoptotic signaling cascade.

The effective use of an endogenous anti-apoptotic protein Bcl$\mathrm{xL}$ has high significance in therapeutic intervention against vascular hyperpermeability. Exogenous administration of $\mathrm{BCl}-\mathrm{xL}$ has been attempted previously. It has been shown that systemic delivery of recombinant $\mathrm{BCl}-\mathrm{xL}$ fusion protein containing the TAT protein transduction domain attenuated neonatal brain damage following hypoxic ischemia in 7-day-old rats, and the TAT-BCl-xL has been shown to inhibit caspase- 3 and -9 activity. ${ }^{28}$ These data suggest that $\mathrm{BCl}-\mathrm{xL}$ is effective against ischemia-induced apoptotic cell death. The protective effect of $\mathrm{BCl}-\mathrm{xL}$ observed in an acute condition such as HS-induced vascular hyperpermeability may be due to its protective effect against adherens junction damage before cell death. We have observed this effect in other studies, where we observed $\beta$-catenin redistribution from cell-cell junctions into perinuclear aggregations following active caspase- 3 transference. ${ }^{9}$ These data suggest that during HS the vascular endothelium undergoes apoptosis, which leads to detachment of endothelial cells. Other laboratories report that endothelialderived microparticles and other common endothelial cell surface markers can be used as biomarkers for acute and chronic pathology. ${ }^{29,30}$ We believe that the endothelium is a sentinel that is sensitive to physiologic changes and as such are susceptible to hyperpermeability following most insults. What we have reported above demonstrates the ability of $\mathrm{Bcl}-\mathrm{xL}$ to reduce vascular hyperpermeability before, during and after HS (see Figure 1b). Reduction of vascular hyperpermeability post HS by an antiapoptotic protein suggests that apoptosis is 'pre-primed', or continuously occurring, in the epithelium. However, what remains to be explored is how these cells recover following insult without total loss of barrier function. Some areas to explore are in shear stress, cell surface receptor trafficking and cell-cell interaction during $\mathrm{HS}$.

In conclusion, our results demonstrate that $\mathrm{rBcl}-\mathrm{xL}$ protein effectively prevents HS-induced vascular hyperpermeability, possibly by inhibiting HS-induced activation of the intrinsic apoptotic signaling cascade. Our study has considerable therapeutic potential against HS-induced vascular hyperpermeability as well as in other types of trauma where activation of the apoptotic signaling cascade is known.

\section{MATERIALS AND METHODS}

\section{Animals}

Adult male Sprague-Dawley rats (250-275 g; Charles River Laboratories, Wilmington, MA, USA) were maintained at Texas A\&M Health Science Center College of Medicine and Scott and White Memorial Hospital animal facility on a $12: 12$-h dark/light cycle, with free access to food and water. The room temperature was maintained at $25 \pm 2{ }^{\circ} \mathrm{C}$. The surgical and experimental procedures used in this study were conducted after approval by the Institutional Animal Care and Use Committee. The facility is approved by the American Association for Accreditation of Laboratory Animal Care in accordance with the National Institutes of Health guidelines.

\section{Reagents}

The test solute used for the vascular hyperpermeability measurements was FITC-albumin obtained from Sigma (St. Louis, MO, USA). The test solution was prepared by dissolving the FITC-albumin in $50 \mathrm{mg} / \mathrm{kg}$ saline. JC-1 (5,5',6,6'-tetrachloro-1, 1',3,3'-tetraethylbenzimidazolylcarbocyanine iodide) was obtained from Cell Technology Inc. (Mountain View, CA, USA). The JC-1 reagent was prepared by reconstituting the lyophilized reagent with DMSO to obtain a $100 \times$ stock solution. Immediately before the experiments, the $100 \times$ solution was diluted 1:100 in $1 \times \mathrm{JC}-1$ assay 
buffer. DMSO at this dilution does not have a significant effect on vascular hyperpermeability. $\mathrm{rBCl}-\mathrm{xL}$ protein obtained from R\&D Systems (Minneapolis, MN, USA) was dissolved in DMSO. BCl-xL was mixed with TransIT (a non-lipid cationic polymer, Mirus Bio-Corporation, Madison, WI, USA) for a final concentration of $2.5 \mu \mathrm{g} / \mathrm{ml}(\mathrm{Bcl}-\mathrm{xL})$ and $10 \mu \mathrm{l} / \mathrm{ml}$ of TransIT based on rat's blood volume. Bcl-xL inhibitor 2-OMeAA was obtained from Sigma. The Bcl-xL inhibitor ABT 737 was a generous gift from Abbot Laboratories (Abbott Park, IL, USA).

\section{In vivo studies}

HS and intravital microscopy. Male Sprague-Dawley rats were fasted for $18 \mathrm{~h}$ before each experiment to minimize the amount of undigested food particles in the intestine. The animals were anesthetized by a single injection of $50 \%$ urethane $(1.5 \mathrm{~g} / \mathrm{kg})$ given intramuscularly. Polyethylene tubing (PE-50, $0.58 \mathrm{~mm}$ ID) was placed into the right internal jugular vein for drug administration and fluid resuscitation and the right carotid artery for blood withdrawal, respectively. The mean arterial pressure (MAP) was monitored continuously using a PE-50 $(0.58 \mathrm{~mm}$ ID) cannula placed in the left femoral artery connected to a blood pressure analyzer (Dig-Med, BPA 400A, Micromed, Louisville, KY, USA). A midline laparotomy incision was made, and the rats were placed in a lateral decubitus position on a Plexiglas platform mounted to an intravital upright microscope (Nikon E600, Nikon, Tokyo, Japan). A section of the mesentery from the proximal ileum was exposed and maintained at $37^{\circ} \mathrm{C}$. The mesentery was superfused with normal saline at $2 \mathrm{ml} / \mathrm{min}$ via cannula while covered with plastic wrap to reduce evaporation. Post-capillary venules with diameters of $20-35 \mu \mathrm{m}$ were selected for study utilizing intravital microscope (Nikon Instruments Inc., Natick, MA, USA). The same venule was studied throughout each experiment. Images were obtained with a Photometric Cascade Camera (Roper Scientific, Tucson, AZ, USA), projected onto a computer monitor and captured digitally on computer disc. Data analysis was performed using MetaMorph 4.5/4.6 (Universal Imaging Corp, Downingtown, PA, USA) ${ }^{31,32}$ The animals were allowed to equilibrate for $30 \mathrm{~min}$ before each experiment. This time period allowed the animals to recover from surgical manipulation. Following the equilibration period, the animals were given FITC-albumin $(50 \mathrm{mg} / \mathrm{kg})$ and baseline-integrated optical intensities were obtained intra- and extravascularly (two sites, same computed areas, the mean values were used). To produce HS, the MAP was decreased to $40 \mathrm{~mm} \mathrm{Hg}$ by withdrawing blood from the right carotid artery into a heparinized syringe. To obtain this level of HS requires the removal of $\sim 50-60 \%$ of the animal's blood volume (level IV shock). After HS, the shed blood plus normal saline was reinfused within $5 \mathrm{~min}$ to maintain a MAP at or above $90 \mathrm{~mm} \mathrm{Hg}$. Mesenteric post-capillary venules in a transilluminated segment of the small intestine were examined to quantitate changes in the FITC-albumin flux. Parameters were recorded immediately after the shock period and at every $10 \mathrm{~min}$ interval for $60 \mathrm{~min}$.

Vascular hyperpermeability in vivo. The rats were divided into the following groups: sham $(n=5)$, shock $(n=5)$ and $\mathrm{HS}$ group plus $\mathrm{BCl}-\mathrm{xL}$ (BCl-xL pre; $n=5)$, given 10 min before the shock period. HS group plus $\mathrm{BCl}-$ $\mathrm{xL}(\mathrm{BCl}-\mathrm{xL}$ during; $n=5)$ given $10 \mathrm{~min}$ into the shock period. HS group plus $\mathrm{BCl}-\mathrm{xL}(\mathrm{BCl}-\mathrm{xL}$ post; $n=5)$ given $10 \mathrm{~min}$ after the shock period. TransIT $(10 \mu \mathrm{l} / \mathrm{ml})$ concentration was determined from previous published data in intact microvessels. ${ }^{11}$ The cocktail was prepared by mixing $200 \mu \mathrm{l}$ of serumfree media with $160 \mu \mathrm{l}$ of TransIT at room temperature for $15 \mathrm{~min}$. Bcl-xL protein was mixed with the prepared TransIT solution and was allowed to equilibrate at room temperature for an additional $15 \mathrm{~min}$. The cocktail was injected intravenously into the internal jugular vein. After $60 \mathrm{~min}$ of peptide delivery, the animals were injected intravenously with FITCalbumin $(50 \mathrm{mg} / \mathrm{kg}$ ) to quantitate changes in the albumin flux, as described above. The FITC-albumin flux was measured by determining the changes in integrated optical intensity. The changes in optical intensity were determined in the extravascular space relative to the intensity inside the lumen. The following formula was used to calculate change in optical intensity; $\Delta l=1-(\mathrm{li}-\mathrm{lo} / \mathrm{li})$, where $\Delta l$ is the change in fluorescence intensity, $\mathrm{li}$ is fluorescence intensity inside the vessel and $\mathrm{lo}$ is fluorescence intensity outside the vessel. ${ }^{31,32}$

Additional experiments were performed to determine whether the attenuation of vascular hyperpermeability by $\mathrm{Bcl}-\mathrm{xL}$ correlated with a reduction in volume necessary to maintain a MAP at or above $90 \mathrm{~mm} \mathrm{Hg}$.

In another set of experiments, Bcl-xL inhibitors 2-OMeAA $(6 \mu \mathrm{g} / \mathrm{ml})$ and ABT $737(40 \mu \mathrm{M})$ were tested for their effect on vascular hyperpermeability. The experimental groups consisted of sham-control $(n=5), 2$-OMeAA $(n=5)$ and ABT $737(n=5)$. The animals were injected intravenously with
FITC-albumin $(50 \mathrm{mg} / \mathrm{kg})$ during the equilibration period, and the FITCalbumin flux was again measured by determining the changes in integrated optical intensity.

\section{In vitro studies}

Mitochondrial ROS formation in vivo. The rats were divided into the following groups: sham-control $(n=5), \mathrm{HS}(n=5)$ and Bcl-xL plus HS $(n=5)$. HS was induced as described above. Visualization and quantification of ROS from the mesenteric post-capillary venules was performed using dihydrorhodamine 123 (DHR 123; $50 \mathrm{mg} / \mathrm{kg}$ ) using intravital microscopy. Images of the mesenteric venules were obtained before the shock period and at $10,20,30,40,50$ and $60 \mathrm{~min}$ into resuscitation. To determine relative expression of ROS, the fluorescent intensity was measured in two areas along the vessel using MetaMorph 4.5/4.6 (Universal Imaging Corp.). Values of DHR 123 fluorescence were expressed as change in intensity over time versus baseline values.

Mitochondrial transmembrane potential in vivo. The rats were divided into the following groups: sham-control $(n=5)$, HS group $(n=5)$ and HS group that received Bcl-xL $(2.5 \mu \mathrm{g} / \mathrm{ml})$. Bcl-xL was given 10 min before the shock period. The mesenteric vasculature was superfused with JC-1 reagent $(1: 100)$ to measure changes in mitochondrial transmembrane potential utilizing intravital microscopy as previously described in our laboratory. ${ }^{22,33}$ The JC-1 reagent was superfused over the exposed mesenteric vessels at a volume of $300 \mu \mathrm{l}$ into a bath of $2 \mathrm{ml}$ of saline. The JC-1 rapidly diffused into the vasculature and was detected in the endothelial cells.

\section{In vitro studies}

Cytosolic cytochrome $c$ levels. The rats were divided into the following groups: sham group $(n=5), \mathrm{HS}$ for 60 min tissue taken at the beginning of resuscitation (HS $T_{0} ; n=5$ ), HS for $60 \mathrm{~min}$ tissue taken at the end of $60 \mathrm{~min}$ resuscitation (HS $\left.T_{60} ; n=5\right)$, a HS $T_{0}$ resuscitation plus $\mathrm{Bcl}$-xL group $(n=5)$ and a HS $T_{60}$ resuscitation plus $\mathrm{Bcl}-\mathrm{xL}$ group $(n=5)$. The cytosolic cytochrome $c$ levels were estimated using a cytochrome $c$ ELISA kit (R\&D systems, Minneapolis, MN, USA). The mesenteric vessels were dissected from the rat, weighed and homogenized in a cold preparation buffer (10 mM Tris- $\mathrm{HCl} \mathrm{pH}=7.5,0.3 \mathrm{M}$ sucrose, $10 \mu \mathrm{M}$ Apoptinin, $10 \mu \mathrm{M}$ Pepstatin, $10 \mu \mathrm{M}$ Leupeptin and $1 \mathrm{mM}$ PMSF). The tissue homogenates were centrifuged (10000 r.p.m. for $60 \mathrm{~min}$ at $4^{\circ} \mathrm{C}$ ), and the supernatant (cytosolic fraction) was collected and subjected to protein estimation. The cytosolic cytochrome $c$ levels were estimated using a cytochrome $c$ ELISA kit (R\&D systems). In brief, the samples were treated with a conjugate reagent (horseradish peroxidase-conjugated anti-cytochrome $c$ polyclonal antibody), transferred to microwell strips coated with anti-cytochrome $c$ antibody and incubated for $60 \mathrm{~min}$ at room temperature. The well contents were discarded and the wells were washed using a wash solution. The samples were then treated with a peroxidase substrate reagent and incubated for $15 \mathrm{~min}$ at room temperature. Following the addition of a stop solution, the optical density of each well was measured at $450 \mathrm{~nm}$. A serial dilution of cytochrome $c$ calibrator was subjected to the assay along with the samples and the values were plotted. The concentration of cytochrome $c$ was calibrated from the standard curve.

Casapse-3 activity. The rats were divided into the following groups: sham group $(n=5)$, HS for 60 min tissue taken at the beginning of resuscitation HS $T_{0}(n=5), \mathrm{HS}$ for 60 min tissue taken at the end of 60 min resuscitation period $\mathrm{HS} T_{60}(n=5)$, a HS $T_{0}$ resuscitation plus $\mathrm{BCl}-\mathrm{xL}$ group $(n=5)$ and a HS $T_{60}$ resuscitation plus Bcl-xL group $(n=5)$. The mesenteric microvessels harvested from the animals were homogenized in caspase- 3 sample lysis buffer provided in the caspase-3 fluorometric assay kit (Calbiochem, La Jolla, CA, USA). The homogenates were centrifuged at $500 \times 9$, and the resulting supernatant was used for protein estimation and caspase- 3 assays. Active Caspase-3 cleaves after aspartate residues in a particular peptide sequence (DEVD). The DEVD substrate was labeled with a fluorescent molecule, 7-amino-4-trifluoromethyl coumarin. The lysates were treated with the substrate conjugate, and the resulting fluorescence was measured in a fluorescent plate reader at $400 \mathrm{~nm} / 505 \mathrm{~nm}$.

Monolayer permeability in vitro. For some studies, blood was collected previously from a group of HS rats, or sham rats, and centrifuged at $6000 \mathrm{r}$. p.m. for 20 min to obtain serum. RLMECs obtained from VEC Technologies Inc. (Rensselaer, NY, USA) were grown as monolayers in transwell 
plates (Corning Life Sciences, Lowell, MA, USA) in complete MCDB-3 media. Sixty minutes before the experiments, the monolayers were incubated in fresh media without phenol red dye. The monolayers were transfected with Bcl-xL $(2.5 \mu \mathrm{g} / \mathrm{ml})$ using Trans $I T$ for $60 \mathrm{~min}$. The cells were then treated with the pro-apoptotic BAK peptide, HS serum $\left(T_{60}\right)$ or caspase-3. Bcl-xL and BAK $(5 \mu \mathrm{g} / \mathrm{ml})$ were exposed to TransIT $(10 \mu \mathrm{l} / \mathrm{ml})$ for $15 \mathrm{~min}$ before exposure to the cells FITC-albumin $(5 \mathrm{mg} / \mathrm{ml})$ was added to the luminal (upper) chamber of the transwell and were allowed to equilibrate for $30 \mathrm{~min}$. Untreated monolayers were used as controls. Previous studies from our laboratory have shown that the transfection medium alone does not induce hyperpermeability in the monolayer. The samples $(100 \mu \mathrm{l})$ collected from the abluminal (lower) chambers were analyzed for FITC fluorescent intensity using a fluorometric plate reader at excitation 494 and $520 \mathrm{nM}$. The data were calculated as percentage of the control (basal) values.

Mitochondrial transmembrane potential in vitro. Mitochondrial transmembrane potential $\left(\Delta \psi_{\mathrm{m}}\right)$ was studied using a cationic fluorescent indicator JC-1 described above. To determine change in $\Delta \psi_{m}$, RLMECs were grown on fibronectin-coated cover glass bottom dishes for $24 \mathrm{~h}$, exposed to media without phenol red for 60 min followed by transfection of $\mathrm{BCl}-\mathrm{xL}$ $(\mu \mathrm{M}) . \mathrm{Bcl}-\mathrm{xL}$-treated or untreated cells were exposed to sham or shock serum for $60 \mathrm{~min}$. Bcl-xL $(2.5 \mu \mathrm{g} / \mathrm{ml})$ was prepared as described above, and transfections were performed for $60 \mathrm{~min}$ as described above. Untreated cells served as controls. The cells were incubated with JC-1 for $15 \mathrm{~min}$ at $37^{\circ} \mathrm{C}$, washed in a JC- 1 wash buffer and observed immediately under a confocal (Olympus Fluoview, Center Valley, PA, USA) microscope for visualization of green and red fluorescence.

Endothelial cell adherens junctions. RLMECs were grown on fibronectincoated 20-mm dishes in complete MCDB-3 media for $24 \mathrm{~h}$. Sixty minutes before the start of experiments, the cells were exposed to low-serum media. The cells were transfected with $\mathrm{Bcl}-\mathrm{xL}(2.5 \mu \mathrm{g} / \mathrm{ml})$ for $60 \mathrm{~min}$. The cells were then treated with HS serum for $60 \mathrm{~min}$. Blood was collected previously from a group of $\mathrm{HS}$ rats or sham rats and centrifuged at 6000 r.p.m. for $20 \mathrm{~min}$ to obtain serum. Bcl-xL was exposed to TransIT $(10 \mu \mathrm{l} / \mathrm{ml})$ for $15 \mathrm{~min}$ before exposure to the cells. ${ }^{8,11}$ Untreated, sham serum-treated, TransIT-alone-treated and Bcl-xL-alone-treated cells served as controls. The cells were washed in PBS, permeabilized with Triton X-100 and fixed with $4 \%$ paraformaldehyde. The cells were then washed in PBS, blocked with $2.5 \%$ BSA-PBS and exposed to a polyclonal antibody against $\beta$-catenin (Santa Cruz Biotechnology, Dallas, TX, USA) overnight at $4{ }^{\circ} \mathrm{C}$. The cells were washed in PBS and exposed to an FITC-tagged ant-rabbit secondary antibody (Santa Cruz Biotechnology). The cells were washed, mounted in an antifade-DAPI mountant and visualized utilizing confocal microscopy.

\section{Statistical analysis}

All values are expressed as mean \pm S.E.M. Statistical analysis was performed utilizing analysis of variance (ANOVA) followed by the Bonferroni's post-test for multiple comparisons. A P'value of $<0.05$ was considered to indicate a significant difference. In vascular permeability studies, each experimental value was compared with the initial baseline value and expressed as the percentage change. This method decreases bias between animals because of hematocrit and changes in room lighting. For all treatments, we did the following analysis. We built a linear model with a time factor and a treatment factor to allow us to do a two-way ANOVA. We also accounted for random variation between rats, by adding in random effects terms. Our outcome of interest, however, was the difference between treatments at each separate time point (for example, between drug and sham, or between $\mathrm{BCl}-\mathrm{xL}$ and so on). This was assessed using pre-planned contrasts from the linear model. Multiple testing was corrected using the Bonferroni correction.

\section{ABBREVIATIONS}

2-OMeAA, 2-methoxy antimycin; $\Delta \psi_{m}$, mitochondrial transmembrane potential; $\Delta l$, change in fluorescence intensity; AFC, 7-amino-4trifluoromethyl coumarin; Apaf-1, apoptotic protease-activating factor-1; $\mathrm{BH}, \mathrm{BCl}-2$ homology; DHR 123, dihydrorhodamine 123; FITC, fluorescein isothiocyanate; HS, hemorrhagic shock; JC-1,5,5'6, 6'-tetrachloro$1,1^{\prime}, 3,3^{\prime}$ tetraethylbenzimidazolyl-carbocyanine iodide; MAP, mean arterial pressure; MTP, mitochondrial transition pore; $r B c l-x L$, recombinant mouse
$\mathrm{BCl}-\mathrm{xL}$; RLMEC, rat lung microvascular endothelial cells; ROS, reactive oxygen species; smac, second mitochondrial-derived activator of caspases; $T_{60}, 60 \mathrm{~min}$ of $\mathrm{HS}$ and $60 \mathrm{~min}$ of resuscitation; $T_{0}, 60 \mathrm{~min}$ of HS and $0 \mathrm{~min}$ resuscitation; TNF $a$, tumor necrosis factor $\alpha$; TRAIL, TNF-related apoptosisinducing ligand.

\section{ACKNOWLEDGEMENTS}

This work was supported by a grant (1K01HL07815-01A1) from the National Heart, Lung and Blood Institute, and (S21MD000101) from the National Institute of Minority Health and Health Disparities, National Institutes of Health. The content is solely the responsibility of the authors and does not necessarily represent the official views of the National Institutes of Health.

\section{COMPETING INTERESTS}

The authors declare no conflict of interest.

\section{REFERENCES}

1 Jones A, Klein J. Shock In: Marx J, Hockberger R, Walls R (eds). Rosen's Emergency Medicine, 2nd edn. Elsevier B.V. Inc: Philadelphia, PA, USA, 2014, pp 67-74.

2 Kauvar DS, Lefering R, Wade CE. Impact of hemorrhage on trauma outcome: an overview of epidemiology, clinical presentations, and therapeutic considerations. J Trauma. 2006; 60(6 Suppl): S3-S11.

3 Davidson MT, Deitch EA, Lu Q. Trauma-hemorrhagic shock mesenteric lymph induces endothelial apoptosis that involves both caspase- dependent and caspase-independent mechanisms. Ann Surg 2004; 240: 123-131.

4 Mauriz L, Gonza P, Jorquera F, Olcoz L. Caspase inhibition does not protect against liver damage in hemorrhagic shock. Shock 2003; 19: 33-37.

5 Nakajima Y, Hiasa Y, Junger WG, Hoyt DB, Ohnishi T. Hypertonic saline resuscitation reduces apoptosis and tissue damage of the small intestine in a mouse model of Yoshinori Murao, Michiaki Hata, Ken Ohnishi, Kazuo Okuchi. Shock 2003; 20: $23-28$.

6 Watts JA, li RMG, Whitlow BS, Kline JA. Activation of poly (ADP-ribose ) polymerase in severe hemorrhagic shock and resuscitation. Am J Physiol Gastrointest Liver Physiol 2001; 2861: 498-506.

7 Childs EW, Udobi KF, Hunter FA, Dhevan V. Evidence of transcellular albumin transport after hemorrhagic shock. Shock 2005; 23: 565-570.

8 Sawant DA, Tharakan B, Wilson RL, Stagg HW, Hunter FA, Childs EW. Regulation of tumor necrosis factor-a-induced microvascular endothelial cell hyperpermeability by recombinant B-cell lymphoma-extra large. J Surg Res 2013; 184: 628-637.

9 Tharakan B, Hellman J, Sawant DA, Tinsley JH, Parrish AR, Hunter FA et al. $\beta$-catenin dynamics in the regulation of microvascular endothelial cell hyperpermeability. Shock 2012; 37: 306-311.

10 Childs EW, Tharakan B, Hunter FA, Tinsley JH, Cao X. Apoptotic signaling induces hyperpermeability following hemorrhagic shock. Am J Physiol Heart Circ Physiol 2007; 292: H3179-H3189.

11 Tinsley JH, Zawieja DC, Wu MH, Ustinova EE, Xu W, Yuan SY. Protein transfection of intact microvessels specifically modulates vasoreactivity and permeability. J Vasc Res 2001; 76504: 444-452.

12 Rathmell JC, Thompson CB. The central effectors of cell death in the immune system. Annu Rev Immunol 1999; 17: 781-828.

13 Ashkenazi A, Dixit VM. Death receptors : signaling and modulation. Science 1998; 281: 1305-1308.

14 Krammer PH. CD95's Deadly Mission in the Immune System. Nature 2000; 407: 789-795.

15 Kuwana T, Bouchier-Hayes L, Chipuk JE, Bonzon C, Sullivan BA, Green DR et al. BH3 domains of BH3-only proteins differentially regulate bax-mediated mitochondrial membrane permeabilization both directly and indirectly. Mol Cell 2005; 17: 525-535.

16 Kroemer G, Dallaporta B, Resche-Rigon M The mitochondrial death/life regulator in apoptosis and necrosis. Annu Rev Physiol 1998; 60: 619-642.

17 Orrenius S Mitochondrial regulation of apoptotic cell death. Toxicol Lett 2004; 149 : 19-23.

18 Green DR, Reed JC Mitochondria and apoptosis. Science 1998; 281: 1309-1313.

19 Ricci J, Gottlieb RA, Green DR Caspase-mediated loss of mitochondrial function and generation of reactive oxygen species during apoptosis. J Cell Biol 2003; 160: 65-75.

20 Kim R, Emi M, Tanabe K Role of mitochondria as the gardens of cell death. Cancer Chemother Pharmacol 2006; 57: 545-553.

21 Petrosillo G, Ruggiero FM, Paradies G. Role of reactive oxygen species and cardiolipin in the release of cytochrome c from mitochondria. FASEB J 2003; 17: 2202-2208. 
22 Tharakan B, Whaley JG, Hunter FA, Smythe WR, Childs EW. (-)-Deprenyl inhibits vascular hyperpermeability after hemorrhagic shock. Shock 2010; 33: 56-63.

23 Kim R, Emi M, Tanabe K. Caspase-dependent and -independent cell death pathways after DNA damage (Review). Oncol Rep 2005; 14: 595-599.

24 Childs EW, Udobi KF, Wood JG, Hunter FA, Smalley DM, Cheung LY. Leukocyte-endothelial adherence following hemorrhagic shock. Shock 2002; 18: 423-427.

25 Childs EW, Tharakan B, Hunter FA, Isong M, Liggins ND. Mitochondrial complex III is involved in proapoptotic BAK-induced microvascular endothelial cell hyperpermeability. Shock 2008; 29: 636-641.

26 D'auria F, Centurione L, Centurione M, Angelini A, Di Pietro R, Di Pietro R. Tumor necrosis factor related apoptosis inducing ligand (TRAIL) in endothelial response to biomechanical and biochemical stresses in arteries. J Cell Biochem 2015; 116: 2427-2434.

27 Miller TM, Moulder KL, Knudson CM, Creedon DJ, Deshmukh M, Korsmeyer SJ et al. Bax deletion further orders the cell death pathway in cerebellar granule cells and suggests a caspase-independent pathway to cell death. J Cell Biol 1997; 139: 205-217.

28 Yin W, Cao G, Johnnides MJ, Signore AP, Luo Y, Hickey RW et al. TAT-mediated delivery of $\mathrm{BCl}-\mathrm{xL}$ protein is neuroprotective against neonatal hypoxic-ischemic brain injury via inhibition of caspases and AIF. Neurobiol Dis 2006; 21: 358-371.
29 Day DE, Oedorf K, Kogan S, Novack V, Sanchez LD, Wolfe RE et al. The utility of inflammatory and endothelial markers to identify infection in emergency department patients. Shock 2015; 44: 215-220.

30 Berezin A, Zulli A, Kerrigan S, Petrovic D, Kruzliak P. Predictive role of circulating endothelial-derived microparticles in cardiovascular diseases. Clin Biochem 2015; 48: $562-568$.

31 Dejana E, Bazzoni G, Lampugnani MG. Vascular endothelial (VE) -cadherin : only an intercellular glue? Exp Cell Res 1999; 19: 13-19.

32 Del Maschio A, Zanetti A, Corada M, Rival Y, Ruco L, Lampugnani MG et al. Polymorphonuclear leukocyte adhesion triggers the disorganization of endothelial cell-to-cell adherens junctions. J Cell Biol 1996; 135: 497-510.

33 Tharakan B, Hunter FA, Smythe WR, Childs EW. A-lipoic acid attenuates hemorrhagic shock-induced apoptotic signaling and vascular hyperpermeability. Shock 2008; 30: 571-577.

This work is licensed under a Creative Commons Attribution 4.0 International License. The images or other third party material in this article are included in the article's Creative Commons license, unless indicated otherwise in the credit line; if the material is not included under the Creative Commons license, users will need to obtain permission from the license holder to reproduce the material. To view a copy of this license, visit http://creativecommons.org/licenses/by/4.0/ 